\title{
Media Hybridization in the MENA Region How Traditional Media Harness Online/Social Transitions for Survival
}

\author{
Mohammad Ayish \\ Professor and Head, Department of Mass Communication, American University of Sharjah \\ Sharjah, United Arab Emirates \\ mayish@aus.edu
}

\begin{abstract}
The huge digital transitions sweeping national and international communications were bound to have an impact on the MENA media landscape. Not only have those transitions induced greater empowerment for individuals and groups in an expanding virtual public sphere, but they have also presented traditional media organizations with some existential challenges. Available data systematically suggest more young people in the region are turning to social and online media as the new frontier for their information consumption. Likewise, there are clear indications that traditional advertising is no longer defining the financial posture of legacy media, especially in view of the global financial crisis and decreasing oil revenues.

The author argues that hybridization of traditional/social/online media operations in the region has emerged as a popular recipe for coming to terms with ongoing digital communications disruptions. More traditional media like newspapers and radio and television services are leveraging the power of social and online media to bolster their positions in a fast-changing communications environment. More of them are going social and online to reach out to a huge audience marked by young demographics and a passion for mobile and app-based news, information and entertainment. Online websites and portals have become distinctive features of traditional media operations in addition to accounts on a wide range of social platforms in the MENA region.

In this article, the author discusses how two satellite television services: Al Jazeera Satellite Channel and BBC Arabic Television draw on hybrid physical resources to optimize audience engagement. It is argued here that in the long run, this hybridization strategy may not prove to be highly successful in view of built-in tensions between two communication models at work and the region's economic and demographic transitions. Traditional communication models draw on one-way flows of information while social models thrive on symmetrical communications and engagements. In addition, with 65\% of the MENA region's populations classified as 'digital generations,' traditional media seem to have lost their appeal. Finally, fallouts of the 2009 financial crisis, aggravated by the 2016 recessions in oil revenues, have accelerated much of the online media migration across the region.
\end{abstract}

Keywords: Hybridization/social/digital/ MENA/disruption

In the past few years, Christenson's notion of disruption (1997) has informed much of the debates on how new information technology innovations are re-defining the concept and practice of business in media industries. Discussions of global corporate transitions have viewed information technologyinduced disruptions as undermining the traditional media business models. Questions raised by those discussions addressed the 'disruptive role' of new digital and social media in the emerging public sphere where legacy media organizations are no longer the sole players. Users' easy access to Web and App-based contents that come in multimedia formats has been viewed as highly detrimental to all traditional media stakeholders, including corporate owners, advertisers, technology providers, producers, talents, and the audiences themselves (Bruhn, Schoenmueller and Schafer, 2012). It has been argued that audiences' access to online content, both as consumers and creators, coupled with the Web's global reach capacity, multimedia format and user engagement, have all diminished the role of mass communications industries as the prime forces defining today's public sphere. Evidence of declining legacy media audiences and advertising revenues has confirmed concerns about the implications of ongoing shifts in the communications sector for the future of the mass communications industry (Newman, et al 2016).

In the past few years, traditional media in the Middle East and North Africa (MENA) region seem to see digital transitions more as unique opportunities for survival rather than as existential threats. This 
study draws on an analysis of how two satellite channels: Al Jazeera Satellite Channel(JSC) and BBC Arabic Television (BBCATV) harness social and online resources to bolster their position on the traditional media map. With a growing integration of social/online features into their operations, traditional print and broadcast media in the region are no longer presenting themselves as physical tools of mass communication. BBC Arabic defines itself as "an integrated news and information service for the Arab World. It is available on air and on demand 24-hours a day, seven days a week" (BBC, 2011). Aljazeera.net, on the other hand, defines its function as 'to complement the pioneering role of Al Jazeera Channel in enhancing written and visual Arab media messages; enabling Arab audiences to engage with news and analyses online and increasing JSC and Aljazeera.net audiences (Aljazeera.net, 2016). This 'hybridization' of social and legacy media into single operational platforms seems to be very much informed by a history of proven 'co-existence' between traditional media formats like the printing press, the telegraph, the telephone, radio and television. But the writer argues that in the context of online/social media, this notion of co-existence seems to be somehow misleading because it obfuscates the unique assimilative power of the Web as a multi-platform media space. Traditional media formats are more likely to continue; however, they would not be operating under separate physical structures, but rather within single Web-based platform with greater userempowered engagement.

\section{Social Media as Disruptive TeChnOlogies}

In the context of the digital/social media revolution, a significant paradigm shift has clearly taken place over the past three decades in how we conceive communication as a key feature of human interaction. If a paradigm shift means a "transformation from one organizing theoretical perspective to another" (Amobi, 2010), then it would be most conspicuous in our new thinking of communication as a two-way process of social engagement. During the dominance of mass media, the all-powerful media theory likened communication to a bullet released at captive audiences, with immediate and direct effects. Audiences were seen as weak and passive subjects who could be easily manipulated (McQuail, 2013). Towards the late 1930s, the limited media effects paradigm was gaining popularity in the context of Paul Lazarsfeld et al research on the 1940 Presidential election that revealed limited media power in affecting public opinion (McQuail, 2009). Further shifts in the communication paradigm were noted in the 1970s and 1980s with the rise of the moderate effects perspective that accounted for numerous mediating factors in defining media effects.

McQuail (2013: 218) observed that by the end of the 20th century, public communication was being better represented by a new paradigm, although no single name has been coined. He noticed (: 218) that nearly all the features highlighted by the idea of mass communication "have been modified or reversed, and additional new possibilities are developing, with different assumptions about the consequences." McQuail (:224) views open access to the Internet as a driver of a multiplication of new entrants as communicators who have engaged in publishing personal weblogs with a range of other possible motivations. He also sees the new form of social media giving rise to new groupings of "inter-communicators," "all linked remotely to each other, but more immediately to innumerable smaller circles of senders and receivers." McQuail's notion of 'inter-communicators' seems to rhyme quite well with Castells' concept of the 'network society' that describes a process of communication involving multiple nodes and two-way flows (Castells, 2000). Both McQuail and Castells see substantive social shifts in this networked structure that promote individual empowerment and independence.

Though transitions in the communication paradigm have generated numerous theoretical perspectives, Christensen's notion of disruptive innovations (1997) has gained considerable attention as a conceptual framework for understanding the impact of technology on the future of companies. Technology, as used by Christensen, means "the processes by which an organization transforms labor, capital, materials, and information into products and services of greater value" (:09). In TheInnovator's Dilemma, Christensen describes how large, successful incumbent organizations were toppled by much smaller start-ups despite the former's adoption of sound management practices. He argues that products based on disruptive technologies are typically cheaper, simpler, smaller, and, frequently, more convenient to use. In addition to the personal desktop computer and discount retailing cases of disruption, Christensen cites off-road motorcycles introduced by Honda, Kawasaki, and Yamaha as disruptive technologies relative to the powerful, over-the-road cycles made by HarleyDavidson and BMW. The dilemma of innovators, according to Christensen, derives from what he 
calls 'the failure framework' that draws on three findings: the distinction between sustaining and disruptive technologies; the observation that technologies can progress faster than market demand, and the conclusion by established companies that investing aggressively in disruptive technologies is not a rational financial decision for them to make (Christensen, 1997:10-12).

Christensen's theory was originally applied to shifting corporate management practices in the context of information technology innovations; however, communication transitions from mass to digital/social modes came to be embraced in the discussions. It was argued that social media have profoundly affected how we communicate in physical and virtual space, by giving rise to more empowered users as full-fledged communicators; enhancing engagement as a key feature of communication; providing multi-media content with more visual and less text content and transcending national frontiers into truly synchronous and globalized platforms. Unlike previous coexisting communication innovations like the printing press, the telegraph, the telephone, radio and television, online/social media have emerged as new platforms of their own with the ability toassimilate other forms of communication in virtual space (Berenger and Taha, 2012). In the emerging social/online sphere, digital content companies like Google and Apple; video platforms like Netflix, YouTube and Snapchat and social media like Facebook and Twitter have been viewed as agents of disruption for legacy mass media. Growing content consumption online, especially in connection with smartphones and tablets, has given more credence to those claims (Newman et. al. 2016).

Since the pace of innovation moves faster than that of projected corporate transitions, the question of adapting to emerging environments would turn out to be a big challenge for business leaders. In the media sector, the fact that most of innovations are coming from competing sectors like telecommunications and information technology giants who also claim a sizable share in the emerging media sector is likely to aggravate the legacy media situation. While traditional media were able to harness the analog-digital transitions of the 1990s to enhance their production and distribution standards, the rise of online/social communications presented them with a real threat. The social transition has been truly disruptive for legacy media simply because it provided audiences/consumers with alternative and more effective modes of communication that derive from a drastically different paradigm. The traditional business model that sees audiences as consumers who are 'sold out' to advertisers in return for advertising dollars is no longer holding in the new communication environment. Audiences are now defined as active users who have the means to access information resources without going through legacy media channels that see communication as an act of manipulation and captivation. In the new social/online media environment, the communication model emphasizes engagement, collaboration, sharing and self-empowerment (Dixon and Keyes, 2013).

The rise of the smart phone as the prime web access point has been a major feature of ongoing media disruptions. Research findings around the world show mobile phones outperforming desktop and laptop computers and tablets in accessing online information and engaging in social space. The Reuters Institute for the Study of Journalism Digital Report (Newman et. al. 2016) noted three trends in digital news industries: the growth of distributed (offsite) news consumption, a sharpening move to mobile and rising ad-blocking practices worldwide. These three trends in combination are putting further severe pressure on the business models of traditional publishers and new digital-born players as well as changing the way in which news is packaged and distributed (:07). In a study of 26 countries in North America and Europe, the Report noted that smartphone usage for news is sharply up, reaching half of our global sample (53\%), while computer use is falling and tablet growth is flattening out. The Report also observed that the biggest change in digital media has been the growth of news accessed via social media sites like Facebook, Twitter, Instagram, and Snapchat. In the United States, for example, the percentage of people saying they use social media as a source of news has risen to $46 \%$ of the sample - almost doubling since 2013 (:09).

\section{The Mena Communications Landscape: An OVervieW}

Although the history of modern media in the Middle East and North Africa goes back to the early $19^{\text {th }}$ century with the publication of the first Arabic newspaper in Egypt (Ayalon, 1995), it was in the postindependence era of the 1960s and 1970s that mass communications came to witness their most significant developments. In the MENA's emerging nations, mass media were seen as credible drivers of national development. Broadcasting in particular was viewed as a powerful instrument of 
education and social awareness and a tool of cultural integration and national expression (Guaaybess, 2013). While newspapers were published and consumed mainly in urban centers, radio and television broadcasting services were harnessed to reach the illiterate and poor masses in the periphery (Boyd, 1999).

By the mid 1970s, all MENA countries had some form of broadcasting operations carrying a range of 'developmental' messages that catered to all sectors of society. As state-controlled organizations, broadcasting services were used to mobilize public support for government development programs and policies and to highlight indigenous heritage and cultural values. Rugh (2005) identified three models of media in the region in the early 1980s: The Mobilization Press, the Loyalist Press and the Diverse Press. While the mobilization model was characteristic of media systems in Egypt, Syria, Iraq and Yemen, the loyalist model was dominant mainly in the monarchist systems of the Gulf region, Jordan and Morocco. The diverse press model embraced media systems in countries like Kuwait and Lebanon. On the other hand, national media systems in the MENA region were not the only sources of news and information. International radio broadcasters in Arabic such as the BBC, the Voice of America and Radio Moscow enjoyed credible exposure in the region. Ayish (1991) notes that the BBC Arabic service was gaining popularity amongst Arab listeners in a region where state-owned communications defined the national public sphere. BBC Arabic radio was found appealing to millions who sought out new perspectives and analyses of the many political developmentsin the MENA region. Ayish (1986) also notes that the Voice of America Arabic service could not match the compelling appeal of the BBC mainly because the former was associated with what most Arabs at the time thought were hostile American policies towards the Arab World. Radio Moscow, on the other hand, was adopting more propagandistic approaches to the region's issues within broader Cold War politics (Boyd, 1999).

By the early 1990s, the media landscape in the MENA region was experiencing significant transformations in the context of globalization with its technological, economic, political and social manifestations. The digital information and communication revolution, as marked by the advent of the Web and satellite television, was impacting the region's media functions and structures. Ayish (2003) notes that the rise of satellite television channels like the Middle East Broadcasting Center (MBC), $\mathrm{Al}$ Jazeera Satellite Channel (JSC), Al Arabiya Channel and hundreds of other transnational television outlets has revolutionized the face of MENA communications. Foreign satellite television broadcasters in Arabic have also come to define the communications landscape in the region. Channels such as BBC Arabic Television, Al Hurra, Russia Today and France 24channels have emerged as key players in shaping the region's evolving public sphere (Ayish, 2008). Satellite broadcasting came to expand in the context of market liberalization and social/political democratization that found expression in an emerging media abundance. Arab audiences, for the first time, enjoyed access to multiple news sources with divergent perspectives about politics and social change. The state-owned and controlled broadcast model was losing ground as digital technologies allowed for multiple channels and a greater transnational reach.

But the most defining feature of the satellite television revolution of the MENA region has been the rise of non-governmental and commercially oriented services alongside state controlled operations (Ayish, 1997). The regional reach of satellite television suggested greater market coverage with a huge consumer base. Advertising became a viable source of funding for private satellite television services especially in the oil-producing nations of the Gulf region. International brands came to find much temptation in satellite television to reach millions of consumers across the Arabic-speaking region. The new business model driving commercial satellite television was based mostly on advertising dollars,albeit in some cases, states continued to maintain subsidies for private services (Sakr, 2006). The rise of commercial television has brought with it more Western-style programming genres that stood in stark contrast to the traditional rigid, visually poor and protocol-oriented content carried by state-owned television (Ayish, 1997). Entertainment content as based on Western reality shows and musical formats has been a newcomer to television shows on commercial television networks.

If satellite television represented the first phase of the digital media revolution in the Middle East and North Africa, the Web has marked the new phase of that revolution. Though the Arab world had its first experience with the Web in the early 1990s, the region continues to have significant variations in terms of access opportunities and usage patterns with GCC states taking the lead. According to the 
ITU statistics, Africa and the Arab States stand out as the regions with the fewest fixed-broadband subscriptions per 100 inhabitants, at less than 1 and less than 4, respectively (ITU, 2015). According to the ITU ICT Report (2015) $40.3 \%$ of households and 37\% of individuals in the MENA region had access to the Internet and $40.6 \%$ had mobile broadband subscription. The ITU's statistics on Mobilecellular telephone subscriptions per 100 inhabitants (2014) show Kuwait leading with 218.83; Saudi Arabia (179.76); the UAE (178); Bahrain (173.27); Libya (161.12); Oman (157.75); Jordan (147.80); Qatar (145.76); Morocco (131.71); Egypt (114.31); Iraq (94.91); Lebanon (88.35) and Palestine (72.08) (ITU, 2015). The Arab Media Outlook (Dubai Press Club, 2016) noted that mobile, apps, the Internet and social media are turning into consumers' first touch points and a way of life. The Report predicts that by 2017 , there will be more smartphone buyers than PC's, making the mobile phone the first screen. In terms of media consumption time, the Report noted that, on average, an individual in the MENA region spent almost 10.9 hours per day consuming media in 2015; marginally up from 10.6 hours per day in 2013. (: 11). With the longest time spent on social networks and mobile videos, digital constitutes $40 \%$ of their attention span with 80 minutes and 28 minutes of time being spent on social networks and video respectively. On the video side, the fastest growing segment is short-form (few minutes long), amateur digital content - curated by Arab youth and distributed on video platforms, such as YouTube(Dubai Press Club, 2016).

The Arab Social Media Report (Arab Social Media Influencers Summit, 2015) notes that social media in the Arab world are perceived as having numerous positive aspects that enhance the qualityof individuals' life, business profitability and governmental interaction with the public (:02). The Report also observes that more than half the users in the Arab World use social media primarily to connect with people while gaining information, watching videos, listening to music and sharing photos came as the second top main reason for using social media. According to the Report, on average, one third of users spend less than 30 minutes per session when using social media, and 5\% spend more than 4 hours per session (: 05). Smart phones are used by $83 \%$ of users to access social media while laptop (11\%); desktop (3\%) and tablet (3\%). Whatsapp and Facebook were the top used social media channels in the MENA region. Across the Arab World, Facebook was the most used social media channel followed by WhatsApp (:21). With regards to Twitter and Instagram, the survey shows that the preference for the two platforms was low for users covered by the survey, as only (4\%) of total users prefer Twitter while only $6 \%$ mentioned Instagram as their favorite tool (:34).

It is clear that the MENA region's digital social revolution is presenting traditional media with both opportunities and challenges as they struggle to enhance engagement with their audience (Ayish and Mellor, 2015). While a social/online media-rich MENA region would beef up traditional media engagement with audiences, it also constitutes a viable communication alternative for millions disenchanted with state-controlled media. In this study, the author argues that the majority of MENA media seem to see emerging social/online outlets more as supportive tools rather than as rivals. All traditional media organizations have thus chosen to maintain their existing functionality and business models while drawing on digital/social tools to expand their reach and optimize engagement with audiences. This has been most conspicuous in their own websites/portals and social media accounts on different platforms. Ayish and Mellor (2015) analyzed social media practices in 10 pan-Arab media organizations and found substantive social integrations in their operations. In addition it was found that media practitioners in those organizations are also involved in the social sphere. Some of those organizations, it was found, have established their own social media departments to coordinate communications with audiences in social space and to divert social traffic to their websites. Interviews with practitioners in those organizations revealed a profound belief in the power of social media to enhance traditional media work and bolster their competitive standing in the public sphere. By creating a virtual structure to support physical operations, media organizations are hybridizing their work practices and outputs to account for new audiences with clear online engagement.

\section{BBC Arabic Television and Al Jazeera Satellite Channels}

BBCATV and JSC use a range of virtual formats that function alongside their physical channels. Those formats include websites; social media accounts and TV show blogs. This section describes those virtual manifestations and discusses their value for the overall media operations of both channels. The author argues that BBCATV and JSC's virtual manifestations are viewed as seamless components of the channels' physical/traditional services. In this context, both BBC Arabic 
Television and Al Jazeera Satellite Channel are studied in their totality as hybridized media outlets that harness virtual and physical means of communication to reach audiences in the MENA region and beyond. This holistic view of both channels as carriers of content in physical and virtual spaces is central to the argument about hybridization as addressed in this study.

\section{BBC Arabic Television in Physical and Virtual Space}

BBC Arabic Television is a news channel broadcasting to the Middle East as part of the British Broadcasting Corporation. The channel has numerous social media accounts and a website. Launched on 11 March 2008, BBC Arabic Television carries a wide range of news and currents affairs shows, some of which heavily draw on new media techniques and tools.

\section{THE BBC ARABIC WEBSITE (HTTP://WWW.BBC.COM/ARABIC)}

This is a multi-platform website that features a wide range of news, features and other forms presented in multimedia formats. The website also hosts live streaming services for both BBC Arabic Radio and BBC Arabic Television. It carries Middle East and international news in text and video formats, giving users the chance to share the stories on social media platforms. It also features the most-read news topics on the website as well as video and audio streams of the most recent newscasts and talk show episodes aired by the BBC. It also includes one section that invites users to give their opinion about issues to be discussed in the Nuqtat Hewar(Talking Point) show. The website also has a photo gallery section that tells stories in visual format in addition to video stories selected by the service for viewer's attention. The website also shows BBC Arabic's social media platforms for users to follow.

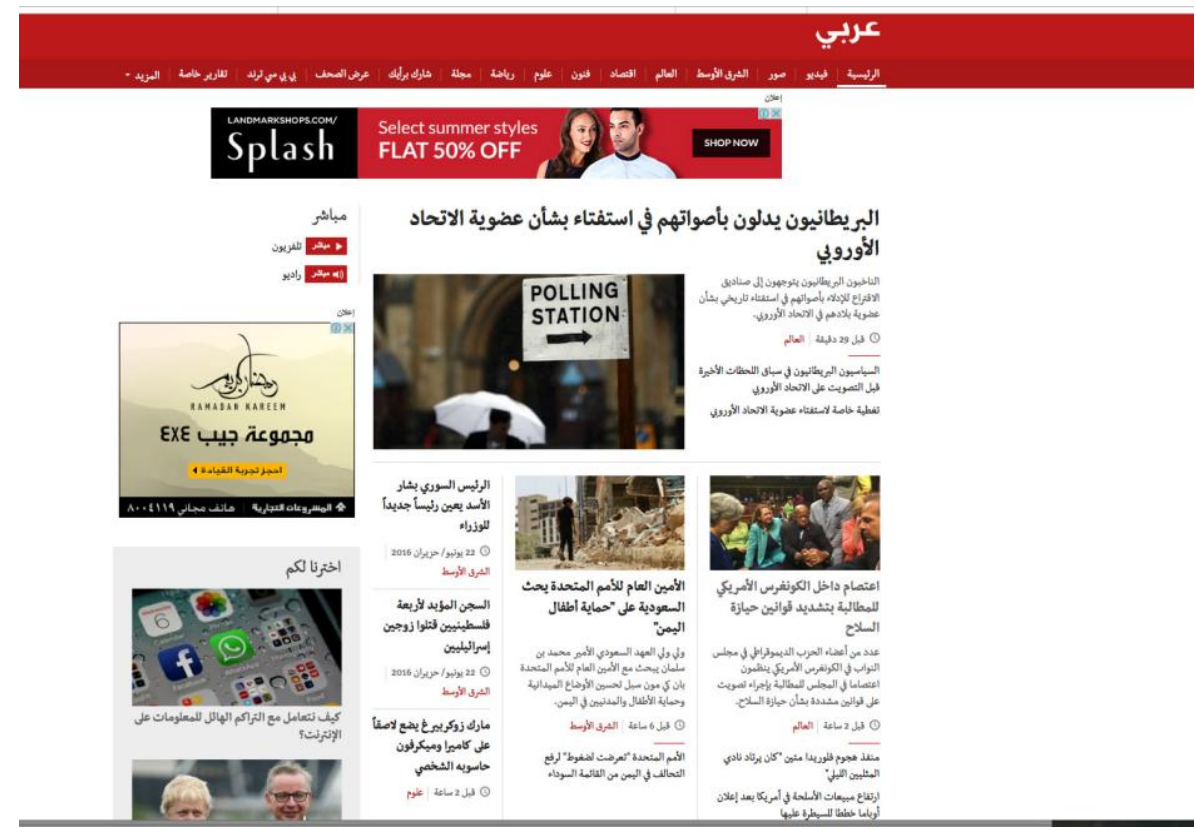

BBC Nuqtat Hewar: (http://www.bbc.com/arabic/tvandradio/2011/01/000000_talking_point)

Nuqtat Hewar "Talking Point" is a nightly talk show that engages viewers in the discussion of issues and events critical to the MENA region. Launched on March 26, 2003, Nuqtat Hewar, went live five days a week with live radio-TV and online transmissions (Abdel Sattar et. al., 2012). Dialogue between Arab citizens in the MENA region and diasporas is enabled through the skillful moderation of the program presenters who contestide as an aggregate user generated content (UGC). Nuqtat Hewar uses a wide range of social media tools in the conversations like Skype, SMS, e-mail, Facebook, Twitter and Instagram. The program ideas are crowd-sourced on Facebook and Twitter to alert viewers and listeners about the upcoming episodes and invite their participation. Ayish and Mellor (2015) noted the following questions were featured in Nuqtat Hewar in early 2014 :(1) what drives highly educated and skilled youth to join Jehadi groups? (2) How do conditions look like in Yemen after tensions arose between Huthis and government forces? (3) How could British Muslims counter extremism? (4) How ready are the Israelis and Palestinians in Gaza to hammer out a peace agreement? (5) What do you think of Syria as the most dangerous place for journalists to work? 


\section{Social Media Platforms}

BBC Arabic maintains a range of social media accounts that are used to enhance audience engagement with the service in its virtual and physical formats. They include Facebook ${ }^{1}$, Twitter ${ }^{2}$, YouTube $^{3}$, Google $+^{4}$, Pinterest ${ }^{5}$, Instagram ${ }^{6}$, Vine ${ }^{7}$, Soundcloud ${ }^{8}$ and Periscope ${ }^{9}$. On June 23, 2016, BBC Arabic had 21,772 followers on Periscope; 7,351,308 likes on Facebook; 3.26 million followers on Twitter; 233,510 subscribers on YouTube; 7,351,308 members on Google+; 329,000 followers on Instagram; and 1100 followers on Pinterest.In their study on social media use by pan-Arab media, Ayish and Mellor (2015) noted that Al Jazeera Facebook traffic from April 1 to August 31, 2014 included 4129 posts, most of them were links to the BBC Arabic website. It was also found that BBC Arabic tweets rose from 45,611 on April 1to 51,022 on August 31, 204. Ayish and Mellor (2015) also noticed that BBC journalists like Samir Farah, Nourddne Zorgui and Rasha Qandeel were actively using both Facebook and Twitter to promote BBC news stories and divert users to the BBC website.

\section{Al Jazeera Satellite Channel in Physical and Virtual Space}

Al Jazeera Satellite (JSC) Channel was launched from Doha, Qatar in 1996 with the declared mission of promoting opinion and the other opinion." (El-Nawawi and Iskander, 2003). Funded by the Qatari government, the channel became part of a global network of six television channels and a news website. JSC gained worldwide attention in the aftermath of the US invasions of both Afghanistan (2001) and Iraq (2003). Over the past few years, Al Jazeera has been at the center of discussions in the Middle East and around the world regarding its news coverage of issues and events during the socalled "Arab Spring". On the other hand, JSC was credited for introducing Western-style news formats to the region and for harnessing the Web to augment its communication with audiences using new media tools and methods. TheEconomist (2011) reported that the staff in Al Jazeera's Arabic and English newsrooms went through intense social-media training only one month before the outbreak of the Arab Spring upheavals. Al Jazeera move meant convincing journalists that social media are not a threat, but "the biggest assets you can have". One of JSC's social engagement shows is Sharek or "share" which allows 'citizen journalists' to upload videos dealing with events in their communities. Instead of flying a reporter somewhere to cover a story, Al Jazeera can draw upon networks of trusted volunteers whose credibility has been established. The show, launched in 2008 , seems to have been inspired by CNN's iReport website (Ulbricht, 2011: 31).

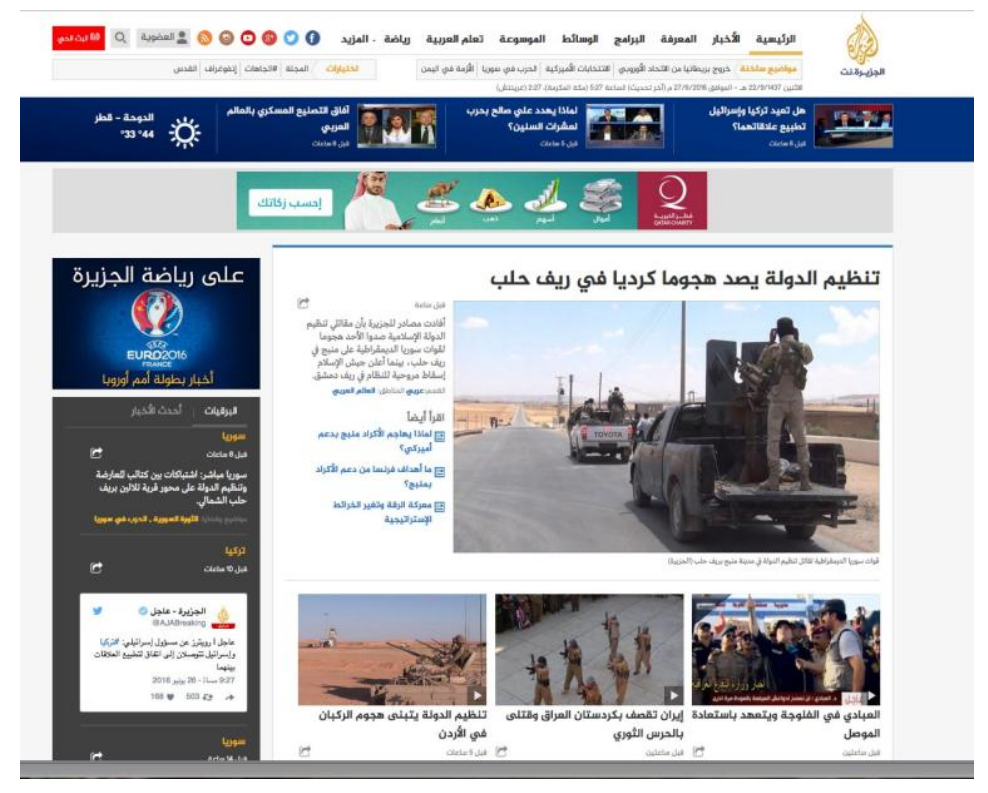

\footnotetext{
${ }^{1}$ https://www.facebook.com/bbcarabic

${ }^{2}$ https://twitter.com/BBCArabic

${ }^{3}$ https://www.youtube.com/user/BBCArabicNews

${ }^{4}$ https://plus.google.com/+bbcarabic/posts

${ }^{5}$ https://www.pinterest.com/bbcarabic

${ }^{6} \mathrm{https}: / / \mathrm{www}$. instagram.com/bbcarabic/

${ }^{7}$ https://vine.co/BBCArabic

${ }^{8} \mathrm{https}: / /$ soundcloud.com/bbcarabic

${ }^{9} \mathrm{http}: / /$ www.periscope.tv/bbcarabic
} 


\section{Al Jazeera Portal (http://WwW.aljaZeera.net/portal)}

Functioning as part of Al Jazeera Network, this portal features a range of headings like News, Knowledge, Programs, Multimedia, Encyclopedia, Learn Arabic, Sports and More. A large number of news items posted on the website have video component and graphics components which enhance the visual outlook of the outlet. The website also includes editorials by leading writers on issues and events impacting the MENA region. The Encyclopedia section hosts a variety of features that deal with historical, cultural and social issues and personalities. The website shows no commercial features with not-for-profit messages displayed. The Sports section enjoys extensive presence on the portal with news and features dealing with local, regional and international sports events. The website also includes links to Al Jazeera's live transmissions and talks shows like 'Opposite Direction,' 'Revolution Talk,' 'Beyond the News,' 'Arab Reality' and 'In Depth.' Links to Al Jazeera social media accounts are provided on the portal to enable users' access to social platforms and their sharing of posted news stories.

\section{Social Platforms}

Al Jazeera Arabic Channel maintains a range of social media accounts to maximize users' engagement with its social contents and traditional television channel programs. Those include: Facebook ${ }^{10}$, Twitter ${ }^{11}$, Google $+{ }^{12}$, YouTube ${ }^{13}$ and Instagarm ${ }^{14}$. As of June 25, 2016, JSC had 15,915,633 Facebook likes, 8.83 million Twitter followers, 1,320,435 followers Google+ followers, 1,029,252 YouTube subscribers and 930,000 Instagram followers. In their 2015 study of social media use by pan-Arab media, Ayish and Mellor (2015) noted that Al Jazeera topped the other outlets in terms of total Facebook likes and growth rates over the study period (April 1-August 31, 2014). During that period, Al Jazeera had 5930 posts with 202 of them coming in multimedia formats. On Twitter, a decline in JSC tweets was noted during the same period for reasons that could not be explained by the authors. Al Jazeera journalists Faisal Al Kasim, Ali Dfiri and Khadija Bin Gana were leading other pan-Arab media journalists in terms of traffic volume and Klout rankings. $\mathrm{Al}$ Kasim had the highest klout score on Twitter (71.6) followed by Dfiri (67.6) and Ben Ganna of Al Jazeera too (61.8).

\section{SHAREK (SHARE) (HTTP://SHAREK.ALJAZEERA.NET/)}

Sharek is an online video-sharing platform created by Al Jazeera to promote the notion citizen journalism among Arabs in the MENA region. The site provides details about individuals who contributed videos in terms of their names, location and profession. It also features tips for optimizing audio-video quality standards in works uploaded to the site. Though uploaded videos cover a range of social, cultural and economic issues, the majority of works submitted on the site come from military/political conflict areas, especially in Syria, Egypt, Gaza, Yemen, Libya and Iraq where JSC journalists had no access. In order to be able to upload videos, 'citizen journalists' need to sign up on the site. An examination of the profiles of contributors shows most of them are young persons with access to mobile devices and Internet connectivity. It was noted that of the 2950 contributors to the site, $75.3 \%$ have details on their portfolios with what appear to be pseudo names and no pictures in order to avoid possible reprisals from authorities in the countries from which they report. Some of them had up to 15 uploads while the majority had inputs ranging from 1-3 videos.

\section{DisCUSSION}

It is clear that both Al Jazeera and BBC Arabic have demonstrated growing engagement with onlinesocial communications alongside their traditional broadcasting operations. Social analytics from a 2015 study (Ayish and Mellor, 2015) and current indicators suggest both broadcasters are defining themselves as more than conventional media channels targeting audiences through electro-magnetic transmissions. Virtual space is becoming a significant communication frontier as both broadcasters seek to attract millions of audiences as active users in their online media platforms. In addition to live broadcasts, the BBC and Al Jazeera Arabic websites feature wide-ranging contents made available to

\footnotetext{
${ }^{10} \mathrm{https}: / / \mathrm{www}$. facebook.com/aljazeerachannel

${ }^{11} \mathrm{https}: / /$ twitter.com/ajarabic

${ }^{12} \mathrm{https} / / /$ plus.google.com/+aljazeeranet/posts

${ }^{13} \mathrm{https}: / / \mathrm{www}$.youtube.com/aljazeera

${ }^{14} \mathrm{https}$ ///www.instagram.com/aljazeeraarabic/
} 
MENA users online. In social space, both broadcasters have cultivated impressive following compared to other pan-Arab media outlets (Ayish and Mellor, 2015). BBC and JSC journalists are also contributing to social traffic with those of Al Jazeera taking a clear political advocacy approach compared to the more professional and non-partisan BBC practitioners. In addition, it was noted that both broadcasters also harness technology-enabled social engagement to beef up their broadcast content. Both BBC Nuqtat Hewar and the JSC Sharek enable viewers to contribute to media content through conversations or video uploads.

But in the context of 'disruption theory,' can we argue that both channels, through their expansion into virtual space, are engaging in some forms of self-disruption? In other words, if both channels, in their physical formats apply traditional communication principles to impact audiences in the MENA region, does their growing engagement with social/online communications constitute an act of selfdefeat? Data on social ad viewership trends for both channels in the past few years suggest that they are cultivating impressive audiences. Al Jazeera claims an audience of 53,208, 177 in the MENA region with a 405 million population (Allied Media City, 2012). Available data show viewers in the 15-39 year age category constitute $45 \%$ of total audiences. In another audience survey conducted by Ipsos and Sigma (Al Jazeera, 2013), Al Jazeera's daily viewership across the MENA region was 34 percent higher than all the other pan-Arab channels combined. BBC Arabic Television also makes similar claims of rising viewership. BBC Audience research findings noted that People across the Middle East have increasingly turned to the $\mathrm{BBC}$ during the 'Arab Uprising' with a record rise in audiences (BBC, 2011). According to the findings, BBC Arabic TV's audience rose to 24.4million from 13.5million - up by more than 80 per cent in late 2011. Overall audiences to the BBC's Arabic services have risen by more than $50 \%$ to a record high of 33.4 million adults weekly - up from 21.6 million before the 'Arab Spring'.

The Arab Media Outlook (2016-19) (Dubai Press Club, 2016) notes that the region's media sector stands at an interesting evolution point. On the one hand, the unique demographics and the fast pace of digitization have created a drive for growth. On the other hand, on macro-economic level, depressed oil prices and political conflicts have created a turbulent environment for media, which is typically vulnerable to economic downturns. The Report observes that the young (under 24) comprise almost a staggering $50 \%$ of the region's population - which is double that of many developed countries like the United Kingdom and the United States. Those youth are shown by successiveArab Media Outlook reports to be the main drivers of social/online media. One study shows that even though new readers are entering the readership age profile in the MENA region, approximately 70 percent of them are skipping the print versions and becoming digital-only consumers (Strategy \&, 2013).

The cases of Al Jazeera Satellite Channel and BBC Arabic Television show that both media services have invested substantially in social media to augment their traditional operations. Both channels see this hybridization as an effective way to sustain their traditional operations while engaging with online/social technological developments. They have, so far, demonstrated credible competency in harnessing the power of social media to expand their audience base and promote their contents across a diverse Arabic-speaking audience. Their social media accounts, according to Ayish and Mellor (2015), have cultivated extensive following as compared with similar pan-Arab media organizations. Their websites feature wide-ranging multi-platform content on the diverse social, cultural, economic issues impacting the MENA region. Their video-sharing and talk show participation platforms also speak to a growing engagement with audiences through synthesized methodologies. Their journalists have taken leading roles as social influencers in the region, capturing substantive following and generating powerful impact.

By incorporating this social/online media component, both services appear to be accentuating their dual character as combined legacy and new media operations. However, from a strategic point of view, this approach may not be sustained in the context of clashing communication paradigms embedded in both forms of media. The process of physical-virtual media hybridization would eventually reach a critical-mass point at which both formats are no longer enjoying a state of coexistence. Deepening engagement with cyberspace, enabled by new generations of smart phones and super-fast connectivity, is bound to drive young users away from legacy media as sources of information and knowledge. As the Arab Media Outlook 2016-19 Report (Dubai Press Club, 2016) 
and other market research findings (Strategy \&, 2013) suggest, there is a steady, albeit slow, departure of youth in the MENA region from traditional media for social/online communications. The rise of digital media platforms dedicated to social and online content consumption like Google, Apple, Netflix, YouTube and BuzzFeed is most likely to accelerate online migration, especially in view of dwindling traditional advertising revenues and advancing mobile and Internet technologies.

\section{Conclusion}

Although social/online media have been successfully harnessed by traditional media in the MENA region to enhance audience engagement and communication reach, the notion of both social and legacy media functioning within the same operations looks rather tenuous. There is consensus among researchers and policy makers that social/online media are performing disruptive functions within hybridized communications environments that would seem hard to sustain in the long term. Demographics, economics and technological developments are inducing growth in online/social migration that increases the stakes for legacy media's future survival. Of course, legacy/social media disengagement is not the recipe for addressing this dilemma. What media organizations in the MENA region need to have is a future vision that sees both media formats as diverging rather than converging.

\section{REFERENCES}

Abdel-Sattar, Nesrine, Mina Al-Lami, Marie Gillespie, Nermeen Sayed, Marayam Wissam (2012) Media And BBC Arabic: A Case Study of Nuqtat Hewar. Research Report June 2012. http://www.open.ac.uk/researchprojects/diasporas/publications/report/bbc-arabic-and-socialmedia-a-case-study-of-nuqtat-hewar

Aljazeera.net. (2016)."Who are We?" Downloaded on June 5, 2016 at: http://www.aljazeera.n et/portal/pages/\%d8\%a7\%d9\%84\%d8\%ac\%d8\%b2\%d9\%8a\%d8\%b1\%d8\%a9-\%d9\%86\% d8\%aa-\%d8\%ac\%d9\%8a\%d9\%84-\%d8\%ac\%d8\%af\%d9\% 8a\%d8\%af

Al Jazeera (2013). "Al Jazeera Arabic tops viewing figures." Downloaded on June 5,2016 at: http://www.aljazeera.com/pressoffice/2013/05/201352291421900835.html

Allied Media City (2012). “Al Jazeera Viewers' Demographics.” Downloaded on June 12, 2016 at: http://www.allied-media.com/aljazeera/al_jazeera_viewers_demographics.html

Arab Social Media Influencers Summit. (2015). Arab Social Media Report. Dubai: TNS.

Ayalon, A. (1995). The Press in the Arab Middle East. New York: Oxford University Press.

Ayish, M. (1986). "The Voice of America between diplomacy and journalism: a case study of the VOA Arabic service." An unpublished doctoral thesis, University of Minnesota, Twin-Cities.

Ayish, M. (1991). "Foreign voices as people's choices: BBC popularity in theArab World,"Middle Eastern Studies, London, July, pp. 374-389.

Ayish, M. (1997). “Arab Television Goes Commercial." Gazette (59) (6). December, pp. 490-501.

Ayish, M. (2003). Arab World Television in the Age of Globalization: An Analysis of Emerging Political, Economic, Cultural and Technological Patterns. Hamburg: Center for Middle Eastern Studies.

Ayish, M. (2008). The New Arab Public Sphere. Berlin: Frank \& Timme.

Ayish, M. and Mellor, N. (2015). Reporting in the MENA Region: Cyber Engagement and Pan-Arab Social Media. London: Rowman and Littlefield.

Amobi, T.I. (2010). "Mass Communication Theories: An Argument for a New Paradigm," in R. Akinfeleye (ed.). Mass Communication: A Book of Readings. Nigeria: Platinum Printing and Packaging Ltd.

BBC (2011). "Record audiences for BBC's Arabic Services.” Downloaded on June 5, 2016 at:

http://www.bbc.co.uk/mediacentre/latestnews/051211arabic.html

Boyd, D. (1999). Broadcasting in the Arab World: A survey of electronic media in the Middle East. Ames, Iowa: Iowa State University Press.

Bruhn, M., Schoenmueller, V and Schafer, D. (2012). "Are social media replacing traditional media in terms of brand equity creation?" Management Research Review, Vol. 35 Iss 9 pp. $770-790$.

Castells, M. (2000). The Rise of the Network Society. Oxford, UK: Blacwell.

Christensen, C. (1997). The Innovator's Dilemma: When New Technologies Cause Great Firms to Fail.Boston, Massachusetts: Harvard Business School Press. 
Dixon, J. and , D. Keyes (2013). "The Permanent Disruption of Social Media," Stanford Social Innovation Review. Winter. Downloaded May 25, 2016 at: http://ssir.org/articles/entry/ the_per manent_disruption_of_social_media.

Dubai Press Club (2016). Arab Media Outlook (2016-19): Youth, Content, Digital Media. Dubai.

Economist (2011). "The People Formerly Known as the Audience," downloaded on May 4, 2016 at: http://www.economist.com/node/18904124.

El-Nawawi, M. and Iskander, A. (2003). Al Jazeera: How the Free Arab News Network Scooped the World and Changed the Middle East. Cambridge, MA: Westview.

Guaaybess, T. (2013). National Broadcasting and State Policy in Arab Countries. New York: Palgrave Macmillan.

International Telecommunications Union. (2015). “Global ICT Developments.” Downloaded on June 5, 2016 at: http://www.itu.int/en/ITU-D/Statistics/Pages/stat/default.aspx.

McQuail, Denis (2014). McQuail's Mass Communication Theory. London: Sage.

McQuail, Denis (2013). "Reflections on Paradigm Change in Communication Theory and Research," International Journal of Communication, 7, Feature 216-229.

Newman, N., Fletcher, D., Levy, A. and Kleis Nielsen (2016). Reuters Institute Digital News Report, 2016. London: Reuters Institute for the Study of Journalism.

Raynor, Michael E. (2011). "Disruption Theory as a Predictor of Innovation Success/Failure," Strategy and Leadership. VOL. 39 NO. 4, pp. 27-30.

Rugh, W. (2004).Arab Mass Media: Newspapers, Radio and Television in Arab Politics. Westport, CT: Prager.

Sakr, N. (2006). "Commercial Interests in the Arab Media," in Emirates Center for Strategic Studies and Research (ECSSR), Arab Media in the Information Age Conference Proceedings. Abu Dhabi: ECSSR, pp. 71-98.

Strategy \& (2013). "Value Retention by Newsprint Publishers in the MENA Region: A ThreePronged Strategy: Optimized Performance, Digital Transformation, Revenue Diversification." London: Booz \& Allen.

Ulbricht, Melissa (2011) “Aljazeera's Curious Experimental Approach, "Rhodes Journalism Review, issue 31, September 2011, pp. 30-31: http://www.rjr.ru.ac.za/rjrpdf/rjr_no31/Al_Jazeeras_curi ous_approach.pdf 